\title{
El problema Pavés. Notas sobre un documento de la Asociación General de Comerciantes del puerto de Valparaíso (Chile, 1921)
}

\author{
The Pavés problem. Notes on a document of the General \\ Association of Merchants of the port of Valparaíso (Chile, 1921)
}

Camilo Santibáñez Rebolledo*

\begin{abstract}
Resumen: Con el objeto de contribuir al estudio de la clase patronal en los puertos chilenos, este texto introduce, reproduce y apunta algunas notas sobre un documento emitido por la Asociación General de Comerciantes de Valparaíso a comienzos de 1921. A partir de su contenido - una serie de dificultades entre la firmante y un agente embarcador -, los apuntes observan un esfuerzo de disciplinamiento en las propias filas patronales como condición de su posterior ofensiva contra los obreros organizados. Según se propone, este requerimiento asociativo resultó crucial en un contexto laboral como el portuario, signado por una multiplicidad de empleadores con escasa capacidad de control sobre trabajadores eventuales.
\end{abstract}

Palabras Clave: Relaciones laborales portuarias, Asociación General de Comerciantes, Valparaíso.

Abstract: In order to contribute to the study of the employer class in Chilean docks, this paper introduces, reproduces and make some notes on a document issued by the General Association of Merchants of Valparaíso at the beginning of 1921. From its content - a series of difficulties with a shipping agent -, the notes suggest an effort to discipline the bosses' own ranks as a condition of their subsequent offensive against organized workers. As proposed, this associative requirement was crucial in a labor context such as the dock one, marked by a multiplicity of employers with little capacity to control casual workers.

Keywords: Dock labor relations, General Association of Merchants, Valparaíso.

* Profesor de Historia y Geografía por la Universidad de Tarapacá y Magíster en Historia de Chile por la Universidad de Santiago de Chile. Actualmente es Profesor Adjunto, Becario ANID y Doctorando en el Departamento de Historia de la Universidad de Santiago de Chile e Investigador Asociado en el Instituto de Estudios Internacionales de la Universidad Arturo Prat. E-mail: sntibaez@gmail.com. ORCID: https://orcid.org/0000-0003-2936-3342. 


\section{Introducción}

D ESE A Su relevancia, la clase patronal ha sido comúnmente relegada en la historia de la conflictividad laboral. Parte del motivo radica en la antipatía que las y los investigadores del movimiento obrero suelen prodigarle, pero la carencia de fuentes documentales también ha impuesto un severo freno a su desarrollo. De acuerdo con Sam Davies, esta "indocumentación" parece corresponder "al lugar poco relevante que ocupa la toma de decisiones sobre asuntos laborales en la jerarquía gerencial", así como a "la reticencia de las empresas a revelar sus políticas laborales, incluso con gran posterioridad a los hechos". ${ }^{1}$

No obstante aquello, este relego ha comenzado a ser corregido durante las últimas décadas mediante una serie de estudios que, además, han puesto de manifiesto la heterogeneidad de esta clase y sus estrategias en las diferentes regiones e industrias. En el caso particular de Chile, las investigaciones de Juan Carlos Yáñez sobre el surgimiento de la legislación laboral y el revisionismo de Sergio Grez sobre los mecanismos de conciliación y arbitraje a principios del siglo $X X^{2}$ inauguraron, hace dos décadas, una línea de investigación cuya rama más consolidada son los estudios sobre el paternalismo industrial; principalmente en la minería y en algunas fábricas. ${ }^{3}$ Sin embargo, y pese a la innegable contribución historiográfica de estos trabajos, el desequilibrio sigue siendo patente en el grueso de las áreas productivas. ${ }^{4}$

El caso de la industria portuaria es paradigmático a este respecto. En Chile, por cierto, pero también globalmente. En su balance realizado a inicios del siglo actual, el mismo Sam Davies remarcó que los empresarios portuarios y sus estrategias no fueron objeto de ninguna monografía durante el referido auge investigativo sobre la clase patronal. Los motivos que halló fueron básicamente dificultades derivadas de la propia industria. En primer lugar, que, sin importar el marco geográfico ni el período, los estudios mostraban "una gran cantidad y diferentes tipos de empleadores en los puertos": el gobierno, autoridades con distintos grados de implicación estatal, grandes y pequeñas compañías navieras, contratistas intermediarios

1 DAVIES, Sam. Employers and dock labor: employment, work and industrial relations in international perspective. En: DAVIES, Sam; DAVIS, Colin J.; DE VRIES, David; VAN VOSS, Lex Heerma; HESSELINK, Lidewij; WEINHAUER, Klauss (ed.). Dock Workers. International Explorations in Comparative Labour History, 1790-1970. Aldershot: Ashgate, 2000, p. 604-605. La traducción es siempre del autor.

2 YÁÑEZ, Juan Carlos. La intervención social en Chile y el nacimiento de la sociedad salarial, 1907-1932. Santiago: RIL Editores, 2008. GREZ TOSO, Sergio. ¿Autonomía o escudo protector? El movimiento obrero y popular y los mecanismos de conciliación y arbitraje (Chile, 1900-1924). Historia, 35, p. 91-150, 2002.

3 FUENTEALBA ROMERO, Nicole. Paternalismo industrial en Chile: Una recopilación historiográfica. Tiempo Histórico, 21, p. 77-100, 2020.

4 Es importante precisar que existe una cantidad importante de estudios sobre empresas y empresarios en la historia de Chile. De hecho, este es el título de una publicación reciente y en dos volúmenes que comprenden el extenso período 1810-2015, editados por Manuel Llorca-Jaña y Diego Barría, con la contribución de una veintena de investigadoras e investigadores. No obstante, y como puede observarse en el metódico balance historiográfico que introduce dicha obra, el ámbito laboral no ha concitado su interés. LLORCA-JAÑA, Manuel y Diego BARRÍA (ed.). Empresas y empresarios en la historia de Chile: 1810-1930. Santiago de Chile: Universitaria. 2017; LLORCA-JAÑA, Manuel y Diego BARRÍA (ed.). Empresas y empresarios en la historia de Chile: 1930-2015. Santiago de Chile: Universitaria. 2017. Ver también: ORTEGA, Luis. Business history in Chile. En: DÁVILA, Carlos y Rory MILLER. Business History in Latin America: The Experience of Seven Countries. Liverpool: Liverpool University Press, 1999, p. 60-82. 
de la estiba, jefes en los muelles, almacenes y bodegas, comerciantes importadores y exportadores, empresas ferroviarias e incluso cooperativas de estibadores. En segundo, que el carácter eventual del trabajo portuario había contribuido a acrecentar un "sentido de distancia" entre los obreros y las navieras dominantes; no sólo porque los primeros solían trabajar para diferentes firmas, sino porque incluso los acuerdos de las navieras con determinadas cuadrillas eran transitorios y estaban entablados a través de agentes intermediarios. El tercer motivo fue que los empresarios implicados tendieron a exhibir serias dificultades para comprender la dinámica mercantil y laboral de los puertos, lo que obviamente afectó su capacidad para sortear los problemas anteriormente enumerados. ${ }^{5}$

Sin tratar el asunto directamente, la historiografía portuaria chilena pareciera ratificar las dos primeras dificultades; esto, al menos en lo concerniente a fines del siglo XIX e inicios del XX, que es el período más acuciosamente estudiado. ${ }^{6}$ Lo referido al tercer asunto, en cambio, es algo todavía difícil de establecer, aunque la capacidad patronal de combatir a los trabajadores organizados mediante lockouts en diferentes regiones y ocasiones del mismo período insinúen lo contrario. De hecho, los antecedentes sugieren que la multiplicidad de empleadores y la existencia de intermediarios no impidió la ejecución de estrategias patronales eficientes en determinadas coyunturas clave, lo que sugiere la utilidad de su examen.

Hasta donde permiten ver los estudios previos, la más relevante de estas coyunturas ocurrió en 1921. Según la nutrida narración que realizó el historiador Peter DeShazo, los Trabajadores Industriales del Mundo (IWW) habían conquistado los muelles de Valparaíso "[aislando] uno a uno a los patrones" mediante "breves paros, boicots y amenazas de huelga" que les significaron arrogarse una serie de mejoras laborales y un control significativo sobre la contratación. Para contrarrestar aquello, los patrones organizados en la Asociación de Comerciantes iniciaron un lockout general el 18 de agosto en el mismo puerto: "Las líneas navieras más grandes y sus contratistas interrumpieron sus operaciones y, al mismo tiempo, la Asociación puso avisos en los periódicos, instando a los trabajadores a firmar su 'registro', que en realidad era un contrato antisindicalista que prometía la no integración a la IWW". El 26 de agosto la Asociación declaró el retorno al trabajo - demostrando lo exitoso de la medida -, pero el 28 la IWW decretó una huelga general que fue secundada por los wobblies en los puertos de Antofagasta y Talcahuano. Lo que, a su vez, fue contestado por las flamantes Asociaciones locales en dichos puertos, también con lockouts. Aunque incluso los inspectores de la Oficina del Trabajo estimaron que esta contraofensiva patronal había sido preparada con el objeto de librarse de "las obligaciones contractuales" y diezmar a los industrialistas,

5 DAVIES, Sam, óp. cit., p. 607-609.

6 SANTIBÁÑEZ REBOLLEDO, Camilo. Posiciones estratégicas y fuerza obrera: Apuntes en torno a un ciclo huelguístico de los estibadores del salitre (Chile, 1916-1923). Izquierdas, 30, p. 188-214, 2016; Ídem. Los trabajadores portuarios chilenos y la experiencia de la eventualidad: Los conflictos por la redondilla en los muelles salitreros (1916-1923). Historia, 50, p. 699-728, 2017; Ídem. Comunidades obreras y propensión a la huelga: Iquique, 1923. Avances del Cesor, 16, p. 161-174, 2019; Ídem. De las tabernas a los sistemas rotativos de contratación: Obreros, capataces y alcohol en las faenas portuarias (Chile, 1914-1923). Estudios Atacameños, 67, 2021. E3636. 
los funcionarios no logaron someter a los patrones a conciliación. Resultando una derrota obrera en todos los puertos "y en especial en Valparaíso, donde la IWW admitió que había sido 'pulverizada' por el lockout'. ${ }^{\text {? }}$

Mi propia revisión de la papelería gubernamental reportó antecedentes que denotan aún más la agresiva supremacía de la Asociación en dicho contexto. ${ }^{8}$ En un telegrama fechado el 27 de agosto - es decir, entre el término del lockout y el inicio de la huelga - el Jefe de la Oficina del Trabajo de Valparaíso telegrafió al Ministerio del Interior señalándole: "La Asociación de Comerciantes ha prescindido de autoridades, ha establecido Oficina de enganche bajo nombre Bolsa del Trabajo, lo que es contrario a disposiciones gubernativas, además ha timbrado con sello Asociación de Comerciantes [las] libretas [de] matrícula, que es un documento nuestro, y ha prohibido la entrada al muelle y [el] acceso a bordo de los que no llevan matrícula timbrada por [ellos]". "Hoy, que la Asociación ha monopolizado el trabajo en Valparaíso y que pretende monopolizarlo en el resto de la República", agregó el funcionario, "nadie puede fiscalizar sus tarifas". ${ }^{9}$

Los hallazgos del historiador Juan Carlos Yáñez sobre el mismo conflicto secundan esta impresión y detectan un indicio fundamental en los mismos documentos. Según pesquisó, la misma Oficina regional aludía a la Asociación como "una entidad comercial de resistencia [que presiona] a las pequeñas casas comerciales en el sentido de obligarlas a acatar sus decisiones". ${ }^{10}$ Una acusación que los empresarios rechazaron, reclamando su legítimo derecho a organizarse y tomar decisiones en defensa de sus intereses. ${ }^{11}$ Sin embargo, la pista es relevante a efectos de entender cómo, pese a su multiplicidad y "distanciamiento", los patrones consiguieron el nivel de asociatividad que les permitió la contestación descrita contra los trabajadores organizados en 1921, en contraste con su aparente docilidad en 1920. El problema, como se indicó en el comienzo, era hallar la documentación que permitiera seguir rastreando estos indicios.

Con dicho objeto, este texto introduce y reproduce un documento emitido por la misma Asociación de Comerciantes de Valparaíso a comienzos de 1921, hallado en las carpetas de la Oficina del Trabajo, en el Archivo Nacional de la Administración. ${ }^{12}$ A partir de su contenido - una serie de dificultades entre la firmante y un agente embarcador -, se apuntan algunos alcances relativos a la "[presión sobre] las pequeñas casas". La hipótesis que guio la lectura del

7 DE SHAZO, Peter. Trabajadores urbanos y sindicatos en Chile, 1902-1927. Santiago: Centro de Investigaciones Diego Barros Arana. 2007. p. 271-274.

8 SANTIBÁÑEZ REBOLLEDO, Camilo. Huelgas y lockouts portuarios por la redondilla. Los conflictos por el control de la contratación en los muelles chilenos (1916-1923). Santiago: Universidad de Santiago de Chile, 2015.

9 Archivo Nacional de la Administración, Dirección del Trabajo (Oficina del Trabajo), Vol. 74.

10 YÁÑEZ, Juan Carlos. Las bolsas de trabajo: Modernización y control del mercado laboral en Chile (19141921). Cuadernos de Historia, 26, 2007. p. 107-134

11 Archivo Nacional de la Administración, Dirección del Trabajo (Oficina del Trabajo), Vol. 74.

12 Es historiográficamente sintomático que, habiendo revisado las mismas carpetas, ningún investigador se detuviera en este documento. Incluso aquellos estudios orientados por la misma problemática. Por ejemplo: MUÑOZ, Nicolás. La huelga portuaria de 1921: La lucha por el control del mercado de trabajo en Valparaíso, Chile. En: Grupo de Estudios Interdisciplinarios del Trabajo, Conflicto laboral y formas de organización del trabajo en Chile. Santiago. 2015. p. 52-75. 
documento es que, durante la segunda mitad de 1920, esta Asociación disciplinó sus propias filas para fortalecer su posición asociativa frente a los obreros. Un requerimiento crucial si las características ya mencionadas de la industria portuaria coinciden con lo planteado por Davies.

En términos más generales, y pese a lo acotado de su origen y objeto, el documento permite escudriñar en las estrategias y prácticas empresariales, allanando la insostenible simplificación historiográfica que caracteriza su lugar en las historias del movimiento obrero. Por ende, esta exploración apuesta también a trazar algunas líneas para la corrección de aquel relego.

Para ello, y de modo previo a su transcripción íntegra, el apartado a continuación brinda algunos elementos contextuales para una mejor comprensión del documento.

\section{Mapa 1: Valparaíso en el cono sur.}

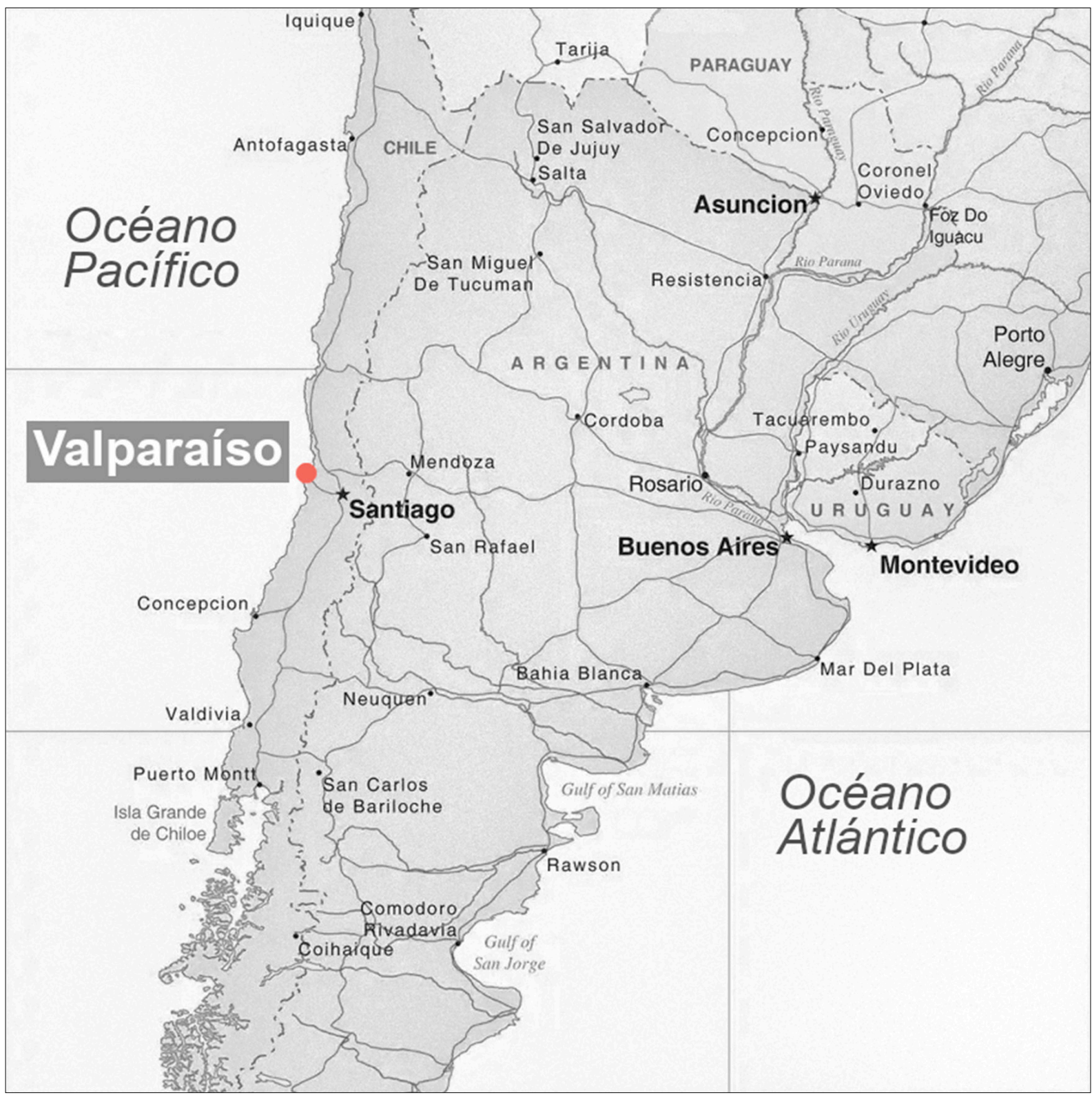

Fuente: Elaboración propia. 


\section{Sobre el puerto de Valparaíso, la conflictividad y sus actores (1917-1921)}

SURGIDO COMO PUERTO colonial de Santiago, Valparaíso creció de forma sostenida con la libertad de comercio resultante del proceso de independencia, tornándose una ciudad boyante y cosmopolita durante el siglo XIX. Hacia sus postrimerías, como apuntó Samuel J. Martland, la ciudad era "un puerto mundial, desde las canciones de marineros hasta las novelas de Julio Verne". ${ }^{13}$ Hasta la década de 1930, de hecho, fue la segunda ciudad más poblada de Chile, y, si bien los extranjeros constituían sólo el $5 \%$ de la clase trabajadora según el censo de 1920, dicho índice se elevaba al $33 \%$ en rubros como la marina mercante. Todo lo anterior signó su relevancia como "centro de la banca, del comercio, de la industria y del transporte". En términos de carga, Valparaíso registraba, hacia 1911, el 11\% del total del tonelaje movilizado por los puertos nacionales; lo que significaba que sus muelles eran los más ajetreados del país tras los de Antofagasta. ${ }^{14}$ Ello es especialmente significativo considerando que fue en 1912 que se iniciaron las obras de construcción del "puerto moderno"; "[el proyecto] de mayor envergadura en el ámbito de las obras civiles en todo el siglo XX". No obstante, la apertura del canal de Panamá, en 1914, relegó a este puerto a la periferia del tráfico internacional, lo que no detuvo su crecimiento, pero sí lo desaceleró de forma severa: las cerca de 1600 toneladas métricas que se movilizaban hacia 1912 - y que duplicaban los índices finiseculares - cayeron, a mediados de la misma década, a cerca de 1.200 y luego, en su término, a 1.000.15

Hacia 1917-1921, no obstante, el puerto seguía reportando un bullicioso movimiento, cuyo correlato laboral estaba signado por el proceso de protesta y represión que los trabajadores y el Estado habían protagonizado en diferentes lugares del país en la década previa. La sanguinolenta clausura de la huelga de 1903, para aludir el caso de Valparaíso, ${ }^{16}$ fue parte de una serie de conflictos que sacudieron la institucionalidad y forzaron el debate sobre la legislación social, al mismo tiempo que sembraron organizaciones obreras de mayor envergadura y con un marcado sello redentorista.

Esto constituyó la coyuntura como una verdadera bifurcación. Fue en 1917 que se establecieron los Tribunales de Conciliación y Arbitraje en el país; ${ }^{17}$ mismo año en que la Federación Obrera de Chile "[rompió] el estrecho círculo del mutualismo y de la personería jurídica", iniciando su conversión en una central roja, al alero del Partido Obrero Socialista. ${ }^{18}$

13 MARTLAND, Samuel J. Construir Valparaíso: Tecnología, municipalidad y Estado, 1820-1920. Santiago: Centro de Investigaciones Diego Barros Arana. 2017. p. 233.

14 DE SHAZO, Peter, óp. cit., p. 35, 37, 54.

15 ORTEGA, Luis, Pamela Araya, Valentina Salas y Sergio Rojas. 100 años de la construcción del puerto de Valparaíso. Historia y legado. Valparaíso: FONDART. 2014. p 17.

16 DE SHAZO, Peter. The Valparaíso maritime strike of 1903 and the development of a revolutionary movement in Chile. Journal of a Latin American Studies, v.11, n.1, p. 145-168, 1979; e ITURRIAGA, Jorge. La huelga de trabajadores portuarios y marítimos. Valparaíso, 1903, y el surgimiento de la clase obrera organizada en Chile. Santiago: Pontificia Universidad Católica, 1997.

17 GREZ TOSO, Sergio, óp. cit.

18 NAVARRO, Jorge. Revolucionarios y parlamentarios. La cultura política del Partido Obrero Socialista, $1912-$ 1922. Santiago: LOM Ediciones, 2017. p. 221. 
Fue en 1918, además, que los Trabajadores Industriales del Mundo (IWW) sentaron su oficina en Valparaíso - y la sección chilena el año siguiente -, reivindicando los métodos de acción directa. ${ }^{19}$ Lo que constituyó un movimiento obrero cuya fisonomía se asemejaba a un monstruo bicéfalo para su clase antagónica.

Es relevante detenerse en las implicancias concretas de las circunstancias referidas. En el caso de los Tribunales de Conciliación y Arbitraje ${ }^{20}$ por ejemplo, su oficialización recogió una experiencia factual documentada desde inicios de siglo. No obstante, su puesta en ejercicio implicó severas fricciones durante varios años. En general, las organizaciones obreras recibieron de forma más entusiasta que los patrones la política estatal, quienes opusieron una dura resistencia a lo largo y ancho de la geografía del país: desde las salitreras hasta la zona del carbón. Cuestión que se enmarcó, además, en un notorio crecimiento y fortalecimiento de los sindicatos urbanos, en medio de las sucesivas crisis de la industria salitrera que jalonaban la economía nacional. Por esto "1919 probó ser el año más propenso a la huelga en la historia de Chile hasta los años cincuenta". ${ }^{21}$

En Valparaíso, particularmente, este robustecimiento obrero se hizo evidente en los conflictos protagonizados por los sindicatos de zapateros, panaderos, obreros gráficos, trabajadores de la construcción y del transporte marítimo. En 1917, de hecho, estos últimos paralizaron la bahía para frenar la imposición gubernamental del retrato obligatorio en sus libretas y alcanzaron una capacidad huelguística superlativa en la víspera de 1921. En el intertanto la tensión se incrementó significativamente por tres razones. En primer lugar, por el fortalecimiento de los IWW en los muelles. Remitiendo el asunto únicamente a 1920, estos hombres "condujeron una serie de huelgas de lancheros", seguidas por una huelga de estibadores, en junio; la que terminó secundada con la paralización total del puerto y les permitió conseguir "todas sus demandas en menos de tres días". Unas semanas más tarde boicotearon a un contratista naviero por no reconocer a un delegado de la IWW y, a mediados de julio, encabezaron una huelga de cargadores, seguida por una nueva huelga general. Según señaló Peter DeShazo, "muchos contratistas se rindieron inmediatamente", "pero los wobblies decidieron [mantener] la huelga hasta que la victoria fuese completa". ${ }^{22}$

19 ARAYA, Mario. Los wobblies criollos: Fundación e ideología en la Región chilena de la Industrial Workers of the World-IWW (1919-1927). Santiago: Universidad ARCIS, 2008; SANTIBÁÑEZ REBOLLEDO, Camilo. La IWW y el movimiento obrero en Chile: El caso de los obreros portuarios nortinos (1919-1923). Diálogo Andino, 55, 2018. p. 19-28.

20 Los Tribunales de Conciliación y Arbitraje permitieron a patrones y trabajadores solicitar el entablamiento de una Junta de Conciliación al intendente o gobernador respectivo para resolver desavenencias en materia laboral. La autoridad debía constituir la Comisión con representantes nominados de forma equitativa por las partes y presidirla. Si esta Comisión no arribaba a acuerdo la misma autoridad debía conformar un Tribunal Arbitral compuesto por un representante de cada parte y un tercero designado por ambas o delegado por el gobierno, cuyo fallo era inapelable. Asumiendo que la negativa de las partes a la conciliación derivaría en huelga - lo que, según la relevancia de la actividad económica, tenía que anunciarse cinco o diez días antes -, la misma autoridad debía oficiar al Ministerio del Interior y a la justicia, e igualmente solicitar la protección policial de los obreros que no quisieran plegarse. Ver: GREZ TOSO, Sergio, óp. cit.

21 DE SHAZO, Peter. Trabajadores urbanos, óp. cit. p. 238.

22 Ibidem, p. 260. 
En segundo lugar, porque esta capacidad obrera fue duramente contestada por el gobierno saliente, encabezado por Juan Luis Sanfuentes. Tras el llamado a huelga general recién comentado, la policía allanó el local la IWW y detuvo a los obreros con evidencia falsa, para luego cerrar sus periódicos y perseguir a sus dirigentes por subversivos - en Valparaíso y en el resto del país. ${ }^{23}$

Finalmente, porque el consecuente arribo del gobierno entrante - encabezado por Arturo Alessandri -, y su compulsiva promoción de los mecanismos de arbitraje, reimpulsó el ímpetu reivindicativo de estos obreros a principios de $1921 .{ }^{24}$ Lo que, en términos sumarios, implicó que "los ministros [y] Oficina del Trabajo se dedicaron a solucionar los conflictos entre los trabajadores y el capital, especialmente en la industria marítima de Valparaíso". ${ }^{25}$ Cuestión que encendió las alertas de combate en el empresariado.

\title{
Documento $^{26}$
}

FUE EN LAS circunstancias antes descritas que la patronal porteña afiató sus filas. Como puede leerse en el documento siguiente, fue durante el invierno de 1920 que organizaron la "Unión" que devino en la Asociación de Comerciantes. Entre los firmantes reconocibles figuran empresarios chilenos y extranjeros, pertenecientes a las casas exportadoras e importadoras, e igualmente a las líneas navieras. Pero no mucho más. Se sabe incluso menos sobre Salustio Pavés, el empresario aludido de forma central en la nota. Básicamente, que era un agente embarcador; lo que, al parecer, lo hacía propietario de algunas lanchas - o, al menos, empleador de la fuerza de trabajo en ellas. También que, en 1918, intentó arrendar un sitio a la Empresa de Ferrocarriles y "destinar el sitio a bodega", aunque sin éxito. ${ }^{27}$ Sin embargo, los problemas entre ambos - la Asociación y Pavés -, quedaron detalladamente estampados en los párrafos a continuación.

\begin{abstract}
La Asociación General de Comerciantes, institución que, como es del dominio del público, ha sido formada por el comercio de Valparaíso con el objeto de armonizar los intereses de patrones y obreros, a fin de evitar los choques y las huelgas que tan nocivos son para los intereses generales, cumple con el deber de poner en conocimiento del comercio y del público en general - a fin de deslindar las responsabilidades que puedan derivarse - la actitud de franca intemperancia y de incumplimiento de compromisos adoptada con sus obreros por el señor Salustio Pavés R., agente embarcador, que efectúa sus faenas usando la concesión del bien fiscal denominado "muelle del carbón", para lo cual cree necesario hacer la siguiente documentada exposición de hechos.
\end{abstract}

23 LAGOS MIERES, Manuel. Los subversivos. Las maquinaciones del poder. "República” de Chile, 1920. Santiago: Quimantú. 2012.

24 El gobierno entrante aludido es el de Arturo Alessandri. Ver: PINTO VALLEJOS, Julio y Verónica Valdivia Ortiz de Zárate. ¿Revolución proletaria o querida chusma? Socialismo y Alessandrismo en la pugna por la politización pampina (1911-1932). LOM Ediciones: Santiago, 2001.

25 DE SHAZO, Peter, óp. cit. p. 267.

26 Archivo Nacional de la Administración, Dirección del Trabajo (Oficina del Trabajo), Vol. 72. La transcripción ha actualizado y corregido ortografía y puntuación.

27 Actas de las Sesiones del Consejo Administrativo de los Ferrocarriles del Estado correspondientes al año 1918. Santiago: Imprenta de los Ferrocarriles del Estado. 1918. p. 1032. 
A raíz de la huelga de los elementos marítimos de junio último, se organizó una "Unión de patrones", que tenía por objeto nombrar una comisión de su seno a fin de que, según compromiso firmado el 5 de julio, "presentara un proyecto de acuerdo tendiente a solucionar las dificultades que se originan con motivo de las continuas huelgas de los gremios marítimos". En cumplimiento de esta misión, la comisión nombrada presentó con fecha 7 del mismo mes un pliego confidencial, que contenía las bases de un comité en el cual los firmantes delegaban su representación para "la fijación de tarifa por los trabajos que se efectúen" y para "buscar un acuerdo con los trabajadores en lo relativo a los jornales y condiciones de trabajo", comprometiéndose cada uno de los firmantes a "no tratar directamente con sus trabajadores". En este compromiso, así como en el mandato de 5 de julio que le dio origen, aparecen las firmas de la mayoría de las casas comerciales marítimas de Valparaíso, figurando entre ellas la del señor Salustio Pavés R., por conducto de apoderado legal.

Como consecuencia de las múltiples gestiones llevadas a cabo por el referido comité patronal, y después de variadas incidencias que son del dominio público, con fecha 23 de julio se firmó un convenio entre patrones y obreros, mediante el cual los gremios en huelga consentían en volver al trabajo, mientras se confeccionaban nuevas tarifas entre patrones y obreros, con el compromiso que dichas tarifas regirían desde la fecha de la reanudación de las labores. Es decir, desde el 24 de julio de 1920, quedando obligados los patrones, por lo tanto, a pagar las diferencias que resultaren el día en que las nuevas tarifas fueran definitivamente aprobadas.

Nuevas gestiones del comité en referencia, asesorado por subcomités dieron por resultado las tarifas de faenas marítimas y del malecón contenidas en la circular $\mathrm{N}^{\circ} 3$ de la Asociación, las que, previa ratificación en la junta general de asociados del 26 de agosto, fueron firmadas por el comité directivo y por delegados obreros debidamente autorizados por sus respectivos gremios, ante el señor gobernador marítimo, capitán de navío don Arturo Acevedo, en los primeros días de septiembre último.

Mientras tanto, el comité directivo, conforme con la autorización confidencial que hemos citado, confeccionaba los estatutos para la organización definitiva de la "Asociación General de Comerciantes", los cuales, aprobados en la misma Junta General a que aludimos en el párrafo anterior, fueron reducidos a escritura pública y firmados ante el notario señor Alberto León Silva por los asociados, contándose entre ellos el señor Salustio Pavés R. En dichos estatutos cada uno de los asociados "comprometen su buen nombre y su buena fe al compromiso de observarlos" y de observar también los acuerdos tomados por el comité directivo de la Asociación, comité que tiene, entre otras, las mismas atribuciones que le fueron conferidas en el compromiso inicial, y cuyo acápite B dice a la letra "Establecer las tarifas de salarios y condiciones de trabajo que deban regir en las faenas de los asociados".

Aprobadas las tarifas en la forma que dejamos expuesta, el presidente de la Asociación envió a los asociados la circular $\mathrm{N}^{\circ} 2$, pidiéndoles que procedieran a pagar las diferencias de jornales, y la $\mathrm{N}^{\circ} 3$ que contenía las nuevas tarifas. Las firmas asociadas en cumplimientos de los compromisos contraídos procedieron en breve a ajustar a sus obreros las diferencias aludidas, sin que ninguna firma pensara siquiera en eludir el compromiso, salvo el caso que nos ocupa.

Así las cosas, con fecha 2 de noviembre último una comisión de jornaleros de la firma del señor Salustio Pavés R., se presentó a la administración de la Asociación, exponiendo "que el señor Pavés se niega a pagarnos la diferencia de jornales procedentes del arreglo de tarifas, a contar desde la fecha de la 
reanudación del trabajo, y también a pagarnos la tarifa general, pretendiendo que aceptemos una tarifa especial elaborada por él, y que escasamente representa el $50 \%$ de los jornales corrientes.

Por otra parte, el señor Pavés nos ha dicho que, si insistimos en llevar adelante nuestro reclamo, se verá precisado a quitarnos el trabajo; y como consideramos que esto no es lo justo ni lo convenido, por insinuación del gobernador marítimo recurrimos a esa Asociación, a fin de que tenga a bien estudiar el asunto y hacer que el señor Pavés reconozca nuestros derechos y nos pague lo que legítimamente nos corresponde".

En atención a esta solicitud obrera y cumpliendo con uno de sus principios objetivos, la Asociación invitó al señor Pavés a exponer las razones que pudiera tener en su abono, y le respondió en extracto que, en primer lugar, reanudadas las faenas había convenido previamente (no obstante el compromiso de "no arreglar directamente con los trabajadores" que había firmado) había convenido previamente, decimos, con sus obreros, el precio de cada trabajo que se presentaba, y que no podía pagar las tarifas de la Asociación porque dentro de los precios establecidos debía deducir los derechos del muelle, bastante subidos, y porque el trabajo en el muelle, por estar dotado de toda clase de elementos mecánicos, era mucho más liviano que el tomado como base para la confección de las tarifas.

La Asociación, en esta emergencia, reunió a la Cámara de Trabajo, y a ella asistieron el señor Pavés y una delegación de sus obreros. Oída la explicación del señor Pavés, los obreros refutaron que no era efectivo que su patrón les consultara antes de hacer algún trabajo acerca del precio, sino que, imponiéndoles el precio a su gusto, amenazaba con hacer tomar preso por los carabineros que custodian el muelle al jornalero que le hiciera alguna objeción, y que, en cuanto a la facilidad del trabajo en el muelle, no era mayor de la que están dotadas las faenas llamadas "de malecón" - es decir, las del sector de Bellavista a Puerto -, para las cuales patrones y obreros convinieron una tarifa más baja, que era la que ellos solicitaban que se aplicara a las faenas del señor Pavés.

Por su parte, la comisión de patrones, además de objetar al señor Pavés que no tenía autorización para contratar directamente con sus obreros tarifas especiales, puesto que había firmado un compromiso al respecto, pudo constatar que no era efectivo que los derechos del muelle afectaran al señor Pavés, pues este señor cobra sus faenas independientemente de esos derechos, siendo estos percibidos directamente por la administración fiscal del muelle, y de cuenta de los dueños o consignatarios de la mercadería.

Después de algunas reuniones preliminares y luego de enterarse detenidamente del problema, estudiándolo en todas sus fases, y aún haciendo una visita ocular a las faenas, la Cámara del Trabajo, organismo de la Asociación, con la ratificación del comité directivo, falló en el sentido de que el señor Pavés debía pagar los trabajos en la forma solicitada por los obreros, es decir, en conformidad de la tarifa de Bellavista a Puerto de la nombrada circular $\mathrm{N}^{\circ} 3$ de la Asociación. Como una concesión a la Empresa de los Ferrocarriles, los obreros aceptaron los precios en las faenas destinadas a dicha empresa.

Resultado de este arreglo fue la firma ante el señor gobernador marítimo, comandante Acevedo, por el señor Pavés y los obreros delegados de sus cuadrillas, con fecha 17 de noviembre último, de un convenio cuyos acuerdos dicen a la letra: 
"Estas tarifas están ajustadas a las de la Asociación General de Comerciantes, sección Bellavista a Puerto, a excepción del carbón y demás materiales de la Empresa de Ferrocarriles del Estado, para los cuales los obreros consienten en hacer una prudente rebaja, en atención a que dicha empresa les proporciona trabajo permanente y es la propietaria del muelle. En consecuencia, el trabajo del carbón de piedra y cocke para particulares, el cobre y demás trabajos no contemplados en esta tarifa, se pagarán ajustándose estrictamente a la expresada tarifa de la Asociación.

Estas tarifas rigen desde el 24 de julio último de acuerdo con el convenio elaborado entre patrones y obreros al reanudarse las faenas después de la huelga, y el señor Pavés se compromete a abonar a sus obreros la diferencia que haya entre esta tarifa y lo que ha pagado desde la fecha indicada hasta el presente.

En caso de que quede algún sobrante procedente de las diferencias de jornales de obreros ausentes de este puerto, este sobrante pasará a poder de la Asociación, y será destinado a incrementar los fondos para la construcción de un mausoleo para la sociedad del personal de remolcadores y donkeros".

Como se ve, con el anterior compromiso el señor Pavés no hacía sino ratificar la expresión de su voluntad, manifestada al firmar los documentos y escritura pública a que hemos aludido antes.

A mayor abundamiento y con objeto de dar término al asunto, el comandante señor Acevedo interrogó al señor Pavés cuándo efectuaría la liquidación de los jornales que reconocía adeudar a sus obreros. Respondiendo, el señor Pavés, fijó una fecha posterior, dándose una semana y fracción de plazo para hacerlo, y el señor gobernador marítimo, conforme con ello, le manifestó que deseaba que el ajuste se hiciera en su presencia.

Antes de expirar ese plazo, que vencía el 29 de noviembre último, los obreros se presentaron a la administración de la Asociación y a la autoridad marítima a expresar que el señor Pavés había contratado una cuadrilla de jornaleros no matriculados, y con ellos estaba efectuando las faenas, dejándolos paralizados. El señor gobernador marítimo impartió las instrucciones del caso, a fin de impedir, en cumplimiento de los reglamentos sobre la materia, el trabajo de obreros no matriculados, a excepción de los que se ocuparan en faenas de la empresa de los Ferrocarriles. Como consecuencia de este incidente, los jornaleros que habían representado sus intereses y los de sus compañeros ante la Asociación y ante las autoridades, fueron despedidos del trabajo por el señor Pavés, quien dio como única razón la voluntad (el capricho, dijo él) del señor administrador del muelle, quien según el señor Pavés, no les permitía entrar a su recinto, no obstante declarar el mismo señor Pavés que el muelle del carbón no está ocupado por concesionarios, sino que es libre, pudiendo hacer faenas por él quien lo desee, sin más que pagar los derechos respectivos.

Venció el plazo fijado y el señor Pavés se presentó ante la autoridad marítima a exponerle que, debido a deficiencias de su contabilidad, no tenía los datos precisos de las faenas efectuadas por sus obreros, por lo que se veía en la necesidad de recurrir a la contabilidad de la administración del muelle, lo que retardaría el ajuste. Con este y con arbitrios y evasivas semejantes, el señor Pavés entretuvo a la autoridad varios días, hasta que el señor gobernador marítimo, deseando de una vez finiquitar este asunto que ya se hacía enojoso, propuso al señor Pavés que un empleado de la gobernación y los obreros delegados le acompañaran en su revisión, a fin de hacerla más rápida. Varias veces fueron los obreros al muelle, premunidos de una tarjeta del señor gobernador marítimo para entrar a él; pero el señor Pavés hizo caso omiso de ellos y la liquidación no se llegó a efectuar. 
Entonces el señor gobernador marítimo comunicó lo ocurrido a la Asociación General de Comerciantes. Se reunió el comité directivo de esta institución, y después de considerar detenidamente el asunto, envió a la autoridad marítima una comunicación en la que le exponía: "que, habiendo agotado, sin resultados positivos, todos los medios a su alcance, la Asociación, declinando en el señor Pavés toda la responsabilidad de lo que pueda ocurrir, cree llegado el caso de dirigirse a US. a fin de entregar a su superior conocimiento estos hechos, cuyos detalles son del conocimiento personal de US. con el objeto de que US. tenga a bien, si así lo estima conveniente, proceder a fallar en este asunto en el sentido que US. estime conveniente de justicia, sin recurso de apelación y con la seguridad de que su fallo comprometerá la gratitud de la Asociación."

Al mismo tiempo, envió al señor Pavés la siguiente carta:

"Cumplimos con el deber de comunicar a Ud. que el comité directivo de esta Asociación, en su sesión reciente, tomó nota de las incidencias producidas alrededor del conflicto habido entre Ud. y sus obreros, por pago de jornales atrasados, y después de considerar detenidamente el asunto por todos sus aspectos, acordó manifestar a Ud. que, habiendo Ud. eludido con toda clase de subterfugios dar cumplimiento a los compromisos contraídos ante esta Asociación y las autoridades marítimas, negándose a pagar las diferencias de jornales a sus obreros, buscando nuevos obreros con menos jornal y aún ejerciendo directa o indirectamente actos de represalia contra los obreros delegados que vinieron a esta Asociación, la institución se ve en la necesidad de advertir a Ud. que está dispuesta a negarle toda ayuda mientras no cumpla estrictamente con sus compromisos, y aún más, que hará cuanto esté a su alcance para obligarlo a ello, haciéndole directamente responsable de todas las dificultades que puedan sobrevenir a consecuencia de su actitud.

La Asociación, como Ud. lo sabe, ha ligado su buen nombre y el prestigio de cada uno de sus asociados al fiel cumplimiento de los compromisos contraídos con los gremios obreros, y en este sentir, condena enérgicamente toda actitud de sus asociados que tienda a burlarlos, pues en el fiel cumplimiento de ellos descansa el prestigio de la institución y la garantía de que en el futuro no se producirán nuevos conflictos entre el capital y el trabajo, nocivos a los intereses generales".

Accediendo a la solicitud de la Asociación, el señor gobernador marítimo ofreció actuar como árbitro para establecer la diferencia que había entre los jornaleros que pagaba el señor Pavés y los que había comprometido a pagar. Tanto los obreros delegados como el señor Pavés aceptaron este arbitraje, y entonces el comandante Acevedo procedió a establecer lo más aproximadamente posible dicha diferencia. Un cálculo muy equitativo, tomando en consideración todos los factores que pudieran contribuir a esa equidad dio una diferencia de $80 \%$. En consecuencia, el señor gobernador marítimo indicó al señor Pavés que debía ajustar a sus obreros la diferencia de jornales atrasados, pagándoles un $80 \%$ de recargo sobre los que le había devengado incompletos desde el 24 de julio hasta esa fecha. El señor Pavés aceptó el fallo, y luego de agradecer al señor gobernador marítimo su resolución, prometió que efectuaría el pago de lo que adeudaba el 7 del corriente, a las 3 de la tarde.

Como se ve, el señor Pavés comprometió su palabra, ratificando por quinta vez lo que prometió bajo su firma en cuatro ocasiones anteriores.

Pero llegó el martes y ocurrió lo que expone el señor gobernador marítimo a la Asociación, en nota de ese día, cuya parte pertinente dice a la letra: 
"El señor Pavés quedó comprometido a efectuar el pago esta tarde a las 3 P. M. en esta oficina, lo que no cumplió, declarando que designaba como su representante para procurar un arreglo con las cuadrillas a un abogado que le acompañaba, faltando abiertamente, por lo tanto, a los compromisos que contrajo en las actas de convenios que suscribió ante esta Gobernación Marítima".

Esta es la palabra oficial del señor gobernador marítimo. Los obreros, por su parte, han declarado a la Asociación que el abogado del señor Pavés les propuso darles una "gratificación" para que desistieran de su reclamo; pero que ellos le respondieron que no aceptaban ningún arreglo que no fuera el pago liso y llano de lo que el señor Pavés les adeuda por diferencias de jornales atrasados, de acuerdo con los compromisos que el señor Pavés ha firmado ante el señor gobernador marítimo.

Para terminar, cabe manifestar que el señor Pavés ha despedido ayer a las cuadrillas de trabajadores a quienes debe jornales ganados con el esfuerzo honrado y laborioso de cada uno de sus nombres, reemplazándolos por individuos inexpertos en esta clase de faenas, y a los cuales abona seguramente jornales que están muy por debajo de los que fijan las tarifas aceptadas por él. Ha dejado desocupados a unos cincuenta hombres, que no han cometido otra falta que reclamar el pago de lo que el señor Pavés les debe, y que ha reconocido adeudarles en documentos firmados por él mismo.

El comité Directivo de la Asociación General de Comerciantes, en vista de esta actitud, acordó dirigirse al señor intendente de la provincia dándole a conocer lo sucedido, así como al señor administrador de los Ferrocarriles, ya que estos acontecimientos se han desarrollado en un sitio de la Empresa, y con el contratista que efectúa los trabajos en esa repartición nacional, esperando que con espíritu de justicia pongan en juego su autoridad para resolver equitativamente esta cuestión.

El comité resolvió también poner en obra otros medios que cree conducentes para conseguir que todo termine, según los deberes y derechos de los obreros y del señor Pavés y que se darán a conocer oportunamente.

Así, pues, la Asociación General de Comerciantes, cuyo comité directivo tiene entre sus atribuciones las de "acordar la adopción de todas las medidas que sean aconsejadas por las circunstancias para alcanzar los fines de la Asociación" aún "en los casos improbables de que alguno de los asociados pusiera resistencia en el cumplimiento de lo determinado en sus estatutos o a los acuerdos del comité directivo", la Asociación, decimos, cumple con el deber de exponer estos hechos, sin añadirles comentario alguno, a fin de que el comercio y el público en general deduzcan lo que estimen de justicia y aprecien con conocimiento de causa las perturbaciones que puedan sobrevenir, y que la Asociación pone bajo la exclusiva responsabilidad del señor Salustio Pavés R.

El comité directivo de la Asociación General de Comerciantes.

Ontoré Plaza, presidente; Juan E. Ortúzar, vicepresidente; Germán Cossio, tesorero; Eduardo A. Vigneaux, secretario; Tomás Linley, J. J. Heavey, Alfonso Bórquez, Luis Luxardo y Alfredo Struve, directores.

[Timbre de la Asociación General de Comerciantes

Enero 1921

Secretaría Valparaíso] 


\section{Notas para el estudio histórico del empresariado en los puertos de Chile}

CON BASE en el documento reproducido, este último apartado ofrece algunos alcances relativos a las prácticas asociativas del empresariado firmante. Para aquello, y recobrando el hilo y el orden argumentativo, se retoman las premisas planteadas por Sam Davies para luego confrontar la hipótesis indagatoria y plantear algunas notas útiles para el estudio histórico del empresariado portuario en Chile.

En primer término, el documento efectivamente corrobora dos de las características que Davies proponía como globales. El asunto de la multiplicidad de empleadores se hace evidente en la superposición de la Empresa de Ferrocarriles que "le proporciona trabajo permanente [a los obreros] y es la propietaria del muelle" y "el contratista que efectúa los trabajos en esa repartición"; forma en la que, aparentemente, la Asociación alude a Pavés. Igualmente, el documento corrobora la debilidad contractual entre patrones y obreros, al comprobar que Pavés se desligó de medio centenar de trabajadores durante los trámites comentados, sustituyéndolos con hombres "inexpertos", que ni siquiera estaban matriculados.

Esta doble comprobación respalda la pregunta que orientó la revisión del documento. A saber: cómo los patrones consiguieron sortear la "multiplicidad" y la "debilidad" contractual que les dificultaba confrontar a obreros con una capacidad asociativa mayor. Cuestión perceptible en las huelgas y especialmente en las tarifas y en las condiciones laborales que estos trabajadores habían impuesto durante 1920, al alero de la IWW.

A este respecto, los antecedentes parecen validar la hipótesis exploratoria. Es decir: que la Asociación General de Comerciantes de Valparaíso fue un esfuerzo patronal deliberado por mejorar su posición en los conflictos laborales; que aquello requería revertir las dificultades antes mencionadas y que para ello tuvieron que castigar al agente que no "[acató] sus decisiones", incurriendo, por tanto, en un acto de disciplinamiento sobre sus propias filas. En concreto, Salustio Pavés fue castigado porque, al desobedecer la negociación sectorial, desconoció y por tanto amenazó el rol y el rango interlocutor de la Asociación. Su disciplinamiento, en consecuencia, buscó fortalecer ambas cuestiones y, con ello, la posición misma de la Asociación.

El motivo original dado por Pavés para su desacato - la incapacidad para pagar las tarifas impuestas -, devela, por cierto, la asimetría patronal en ese disciplinamiento y sugiere el costo que el mismo debió tener para "las pequeñas casas". Lo que plantea al menos dos preguntas. La primera es por la representatividad del caso. Es importante despejar si lo de Pavés fue una excepción o si el fortalecimiento patronal efectivamente fue construido sobre la ruina de los empresarios incapaces de someterse a las determinaciones de las firmas dominantes. 
La segunda es por lo acontecido con las "pequeñas casas" durante la ofensiva patronal de 1921 y por el lugar que ocuparon en la configuración resultante. Pues, lógicamente, es el tamaño presupuestario de una empresa lo que determina su capacidad para soportar una estrategia confrontacional de esta naturaleza. Hay registros de que, hacia septiembre de 1921: “[Los] vapores armadores de la Asociación [rechazaron] toda especie transportada por lanchas de Pavés a [los] vapores y se [negaron] a entregar mercaderías que se [trataran de] descargar por las mismas". Lo que llevó a un parlamentario del Partido Demócrata a interpretar que la Asociación de Comerciantes se había vuelto "un verdadero soviet". ${ }^{28}$ No parece haber más antecedentes, pero la pista merece ser seguida. Incluso al margen de su representatividad.

Finalmente, el documento presenta algunos indicios cuyo ahondamiento permitiría ubicar los sucesos de 1921 y sus implicancias laborales en marcos más amplios. Por ejemplo, lo relativo al destino de los excedentes de la deuda contraída por Pavés. El documento indica que estos iban a ser reservados para "la construcción de un mausoleo para la sociedad del personal de remolcadores y donkeros". Lo que sugiere una estrategia patronal que delata su arraigo en las asistencias propias de los gremios de obreros marítimos formados y regidos por el Estado durante el siglo XIX. Particularmente, su rol como caja de ahorros y como sociedad de socorros mutuos. ${ }^{29}$ Empero, al remitirse los estudios sobre 1890-1920 a la conflictividad, ${ }^{30}$ dicha continuidad es, todavía, un cabo suelto.

Por ello es importante interrogar también la trayectoria de las Asociaciones de Comerciantes de Valparaíso, Antofagasta y Talcahuano con posterioridad a 1921; pues se ignora su vínculo filial con la Cámara Marítima Portuaria, la organización patronal más relevante del siglo XX en los puertos chilenos. Tras su creación, en 1944, ${ }^{31}$ dicha organización asumió la representación empresarial en las negociaciones tripartitas de los años sesenta y setenta; orientó luego el desmantelamiento dictatorial de las conquistas obreras en los terminales marítimos (1981-1990) y ha protegido dicho legado hasta la actualidad. De modo que la reconstrucción de esta eventual continuidad permitiría trazar la asociatividad patronal y su comportamiento en los puertos del país durante el último siglo.

En suma, y pese a corresponder a una industria específica, estos apuntes buscan retomar un asunto tan relevante como poco atendido por la historiografía del conflicto laboral. Esto es: que las estrategias de la clase empresarial obedecieron a la defensa de sus intereses respecto de su clase antagónica. Lo que obliga a tomar en serio aquel axioma tan citado,

28 Cámara de Diputados, Sesión 64ª ordinaria en 1 de septiembre de 1921.

29 YÁVAR MESA, Aldo. El Gremio de Jornaleros y Lancheros de Valparaíso, 1837-1859. Etapa de formación. Historia, 24, 1989. p. 319-395; GREZ TOSO, Sergio. De la "regeneración del pueblo" a la huelga general. Génesis y evolución histórica del movimiento popular en Chile (1810-1890). Santiago: RIL Editores, 2007. p. 258-268; y PINTO VALLEJOS, Julio. En el camino de la Mancomunal: Organizaciones obreras en la Provincia de Tarapacá, 1880-1895. Cuadernos de Historia, 14, 1994. p. 81-136.

30 Ver la sexta nota al pie de este artículo.

31 https://www.camport.cl/somos/ 
según el cual "la noción de clase entraña la noción de relación histórica". ${ }^{32}$ Si documentos como el revisado comportan una buena entrada para examinar aquel entrañamiento, además, ello se debe a que permiten observar los conflictos que dicha relación antagónica le impone internamente a las clases. Lo que implica asumir que la clase patronal también estuvo presente en su propia formación. Y ello no puede seguir ignorándose.

Recebido em 21/04/2021

Aprovado em 03/08/2021

$\overline{32}$ THOMPSON, E. P. La formación de la clase obrera en Inglaterra. Madrid: Capitán Swing. 2012. p. 27. 